\title{
IMPLEMENTASI ALGORITMA BACKPROPAGATION UNTUK MEMPREDIKSI JUMLAH PENGUNJUNG WISATA MUSIUM (STUDI KASUS DI MUSIUM SUNAN DRAJAT)
}

\author{
Muhammad Hasan Wahyudi ${ }^{1}$, Purnomo Hadi Susilo ${ }^{2}$ \\ 1,2) Teknik Informatika, Fakultas Teknik, Universitas Islam Lamongan \\ Jalan Veteran No. 53A, Jetis, Lamongan, Kabupaten Lamongan, Jawa Timur 62211, Indonesia \\ Email:hasanwahyudi@unisla.ac.id ${ }^{1)}$,purnomo@unisla.ac.id ${ }^{2)}$
}

\begin{abstract}
ABSTRAKS
Metode peramalan dalam teknologi komputasi sangatlah beragam, beberapa metode yang ada antara lain Peramalan ARIMA, Adaptive Neuro-Fuzzy Inference System (ANFIS), dan Jaringan Saraf Tiruan (JST). Pada artikel ini menyampaikan tentang usaha sebuah penelitian dengan tujuan untuk menerapkan dan mengetahui kinerja jaringan saraf dalam memprediksi jumlah pengunjung wisata museum (studi kasus di musium Sunan Drajat Lamongan). Metode yang digunakan adalah Matlab yang digunakan untuk menganalisis sebuah data yang kemudian dibentuk sebuah arsitektur jaringan terbaik aktif meramalkan jumlah pengunjung musium Sunan Drajat dengan skema 2-6-1 (2 neuron masukan, lapisan tersembunyi 6 neuron, satu neuron output) dengan nilai MSE terkecil 0,00000000277. Nilai MSE selama pelatihan sebesar 7858.75 sedangkan pada saat pengujian di 5.309.807.667. Kesalahan rata-rata hasil simulasi peramalan jumlah wisatawan ke musium Sunan Drajat dalam periode dari Maret hingga Mei 2019 sebesar 9,5\%.
\end{abstract}

Kata kunci : peramalan, jaringan syaraf tiruan, backpropagation.

\begin{abstract}
Forecasting methods in computing technology are very diverse, several existing methods include ARIMA Forecasting, Adaptive Neuro-Fuzzy Inference System (ANFIS), and Artificial Neural Networks (ANN). This article describes a research effort with the aim of applying and knowing the performance of neural networks in predicting the number of visitors to museum tours (a case study at the Sunan Drajat Lamongan museum). The method used is Matlab which is used to analyze a data which is then formed a best network architecture that actively predicts the number of visitors to the Sunan Drajat museum with a 2-6-1 scheme (2 input neurons, 6 hidden layers of neurons, one output neuron) with the smallest MSE value. 0.00000000277. The MSE value during training was 7858.75 while at the time of testing it was 5,309,807,667. The average error in the simulation results in forecasting the number of tourists to the Sunan Drajat museum in the period from March to May 2019 is $9.5 \%$.
\end{abstract}

Keywords: forecasting, artificial neural networks, backpropagation.

\section{PENDAHULUAN}

Jawa timur adalah sebuah provinsi yang kaya akan wahana pariwisata, mulai dengan yang bersifat hiburan, keindahan alam, religi, dan juga wawasan pengetahuan tentang sejarah atau dikenal dengan museum. Pada wilayah Jawa Timur sendiri tertidiri berbagai wilayah yang mempunyai ciri khas dan keistimewaan masing -masing. Salah satunya adalah kota Lamongan. Kota Lamongan adalah kota yang memiliki banyak unsur keindahan alam sebagai asset pendapatan sebuah daerah, seperti adanya zona pariwisata Goa Maharani, Tanjung Kodok, dll. Namun di kota Lamongan pula terdapat sebuah makan Wali Songo yang merupakan sisi lain dari daya tarik kota Lamongan. Sehingga menjadi sorotan masyarakat terkait adanya wisata religi di Lamongan, tepatnya di desa Drajat.
Wisata religi di Drajat, Lamongan ini dinamakan wisata religi Mbah Sunan Drajat. Para wisatawan yang datang ke makam Sunan Drajat sangatlah banyak. Bahkan menjadi tujuan utama para insan di dunia pendidikan terutamanya untuk ngalap barokah ke mbah Sunan Drajat. Disampung itu pula banyak masyarakat umum yang juga sangat mempercayai adanya barokah doa dengan melalui wasilah ke mbah Sunan Drajat. Keberadaan adanya makam mbah Sunan Drajat ini merupakan sebuah barokah bagi masyarakat drajat pada umumnya. Berbagai toko jajan, baju khas wali, dll. telah memenuhi arah jalan para wisatawan yang akan kembali/pulang. Tidak hanya itu, wisata religi ini juga terdapat sebuah museum bersejarah tentang perjalanan Sang Wali. Wisata musium Sunan Drajat telah menjadi tujuan kedua setelah berkunjung untuk ziarah makam Mbah Sunan Drajat. 
Jumlah pengunjung / wisatawan religi tiap bulannya tidak pernah berkurang dari 10.000 orang. Dengan semakin bertambahnya pengunjung wisatawan, maka tempat peristirahatan dan tempat ibadah sebagai pendukung pelayanan para wisatawan perlu dipertimbangkan. Untuk dapat mengantisipasi jumlah kedatangan wisatawan, maka diperlukan adanya sebuah peramalan jumlah kedatangan pengunjung untuk menganalisa sarana dan prasarana pendukung untuk pelayanan para wisatawan. Dengan adanya peramalan tersebut diharapkan dapat menganalisa secara cepat dan akurat jumlah kedatangan wisatawan ke musium Sunan Drajat.

Metode peramalan sangatlah banyak dalam dunia statistika matematika. Beberapa meotode tersebut antara lain ; simple regression analysis (SRA), decomposition, exponential smoothing (ES), autoregressive integrated moving average (ARIMA) dan seasonal autoregressive integrated moving average (SARIMA) [1-3]. Namun dari beberapa metode tersebut masih memiliki banyak kekurangan dalam menghitung akurasi peramalan, selain itu data yang digunakan harus bersifat linear [4-7].

Mempertimbangkan beberapa kelemahan dari metode statistik tersebut di atas, sehingga banyak peneliti menerapkan metode jaringan syaraf tiruan (JST) dengan berbagai algoritma pelatihan untuk mendapatkan hasil peramalan yang lebih baik, sehingga kelemahan metode statistik telah terselesaikan dengan metode baru tersebut [8]. Selain itu metode JST ini sangat baik digunakan pada data deret waktu yang bersifat tidak linear (nonlinear). Penelitian terbaru menyebutkan bahwa metode jaringan syaraf tiruan (JST) sangat baik dalam meramalkan turis di Mozambique (Januari 2004Desember 2013). Model akurasi JST terbaik dinyatakan dengan nilai MSE terendah [9]. Hal ini menegaskan bahwa metode jaringan syaraf tiruan (JST) masih relevan untuk digunakan [10].

Melihat latar belakang di atas, dalam penelitian ini penulis mencoba untuk mengusulkan sebuah metode Jaringan Syaraf Tiruan Backpropagation. Dengan harapan dapat membantu pemeritah daerah untuk memprediksi jumlah kedatangan wisatawan musium, sehingga dapat dijadikan referensi dalam pemberian layanan terbaik bagi wisatawan.

\section{BAHAN DAN METODE}

Penelitian yang telah dilakukan terkait dalam topik "Implementasi Algoritma Backpropagation untuk Memprediksi Jumlah Pengunjung Wisata Musium telah dilakukan peneliti dengan melalui beberapa tahapan, yakni ; 1). studi literature, 2). pengambilan data yang langsung kami lakukan secara observasi dan wawancara langsung kepada petugas jaga museum "Sunan Drajat" di Paciran, Lamongan. Data yang diambil dijadikan data latih dan data uji. Pada proses yang didapat dalam memprediksi jumlah kedatangan pengunjung pariwisata museum "Sunan Drajat".

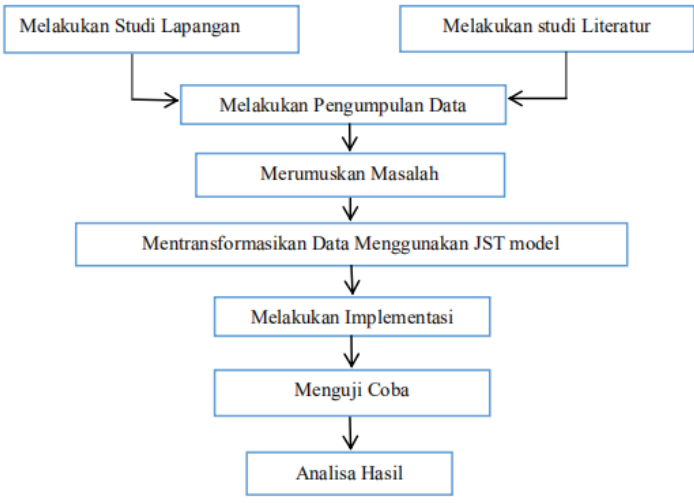

Gambar 1. Metodelogi Penelitian

Penelitian dilakukan menggunakan data primer yang diperoleh dari pengelola musium "Sunan Drajat", yaitu mengenai jumlah kunjungan wisatawanbulan Januari 2016 sampai dengan Desember 2019 sebanyak 48 data, dimana data akan dibagi menjadi dua, yaitu data pelatihan dan data pengujian.

Metode yang digunakan pada penelitian ini adalah Jaringan Syaraf Tiruan dengan algoritma pembelajaran backpropagation menggunakan software Matlab. Proses pembelajaran pada algoritma backpropagation dilakukan dengan menyesuaikan bobot-bobot jaringan syaraf tiruan dengan arah mundur berdasarkan nilai error dalam proses pembelajaran (Kusrini dan Emha Taufiq Luthfi, 2009).

Data pelatihan berupa pasangan data masukan (input) dan keluaran aktual (target) yang diberikan pada jaringan untuk dilatih polanya. Data training yang digunakan adalah data pada bulan Januari 2016 sampai dengan bulan Desember 2018, sedangkan data pada bulan Januari 2019 sampai dengan Desember 2019 digunakan untuk testing.

Pada peneltian ini, Tahap awal yang harus dilakukan adalah menentukan sebuah arsitektur jaringan yang hndak digunakan pada implementasi pelatihan dan pengujian. Peneliti mencoba menggunakan arsitektur jaringan layar banyak (Multi Layer Network) yang mempunyai input, output, dan hidden layer. Tahap berikutnya adalah menentukan algoritma pembelajaran yang digunakan. Algoritma yang digunakan pada penelitian kali ini adalah dengan sebuah metode pembelajaran backpropagation. Selanjutnya, peneliti menentukan data training yang diberikan pada jaringan untuk dilatih polanya. Jaringan diberikan bobot dan bias awal dengan bilangan acak paling kecil. Sinyal masukan dipropagasi ke layar tersembunyi (hidden layer) menggunakan fungsi aktivasi yang ditentukan. Output dari setiap unit layar tersembunyi kemudian dipropagasi maju lagi sampai menghasilkan keluaran jaringan. Nilai selisih antara keluaran jaringan dan target yang harus dicapai diisebut nilai kesalahan. Nilai kesalahan digunakan untuk menghitung nilai 
faktor yang dipakai untuk mendistribusikan kesalahan di unit keluaran ke semua unit tersembunyi.

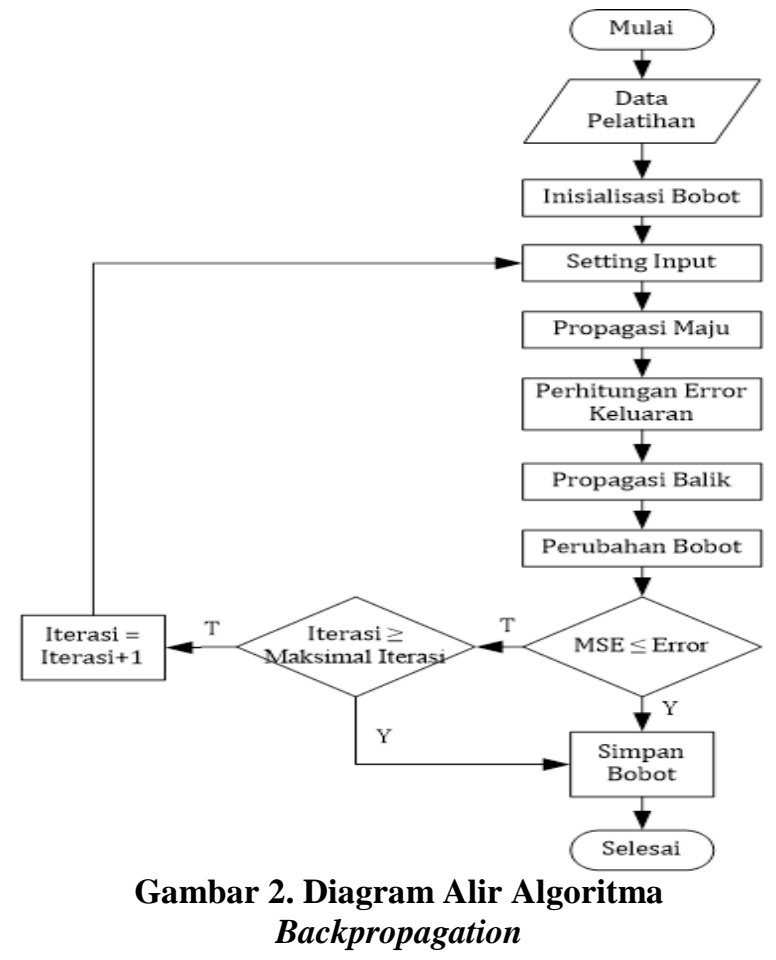

Dari ketiga tahap di atas akan diulang hingga kondisi penghentian dipenuhi. Kondisi penghentian tercapai jika MSE (Mean Square Error) telah mencapai harga minimum epoch atau epoch sama dengan batas toleransi yang diberikan. Nilai MSE pada satu siklus pelatihan adalah nilai kesalahan $($ error $=$ nilai keluaran - nilai masukan $)$ rata-rata dari seluruh record. Semakin kecil MSE, semakin kecil kesalahan Jaringan Syaraf Tiruan dalam memprediksi pola dari record yang baru. Maka pelatihan Jaringan Syaraf Tiruan ini ditujukan untuk memperkecil MSE dari satu siklus berikutnya sampai selisih nilai MSE pada siklus ini dengan siklus sebelumnya lebih kecil atau sama dengan batas minimal yang diberikan. Output peramalan terbaik akan tercapai hingga kondisi penghentian dipenuhi. Kondisi penghentian yang dipakai adalah jumlah iterasi yang ditoleransi sebesar 1000 epochs. Iterasi sebesar 1000 dipilih berdasarkan nilai default iterasi. Nilai iterasi yang terlalu kecil akan menunjukkan hasil yang kurang akurat, sedangkan bila iterasi terlalu besar akan menyebabkan pelatihan jaringan yang terlalu lama.

\section{HASIL DAN PEMBAHASAN}

Pada tahun 2016, jumlah wisatawan yang datang ke musium sunan drajat sebanyak 208.786 wisatawan dengan jumlah kunjungan tertinggi terjadi pada bulan November 2016 dengan jumlah wisatawan sebanyak 23.126 orang dan jumlah kunjungan terendah terjadi pada bulan Agustus 2016, yaitu sebanyak 10.245 wisatawan. Jumlah wisatawan yang datang ke musium sunan drajat pada tahun 2017 mengalami peningkatan sebanyak 411 wisatawan dengan jumlah wisatawan terbanyak pada bulan Juli 2017 sebanyak 25.252 wisatawan dan terendah pada bulan Agustus 2017 sebanyak 10.656 wisatawan. Pada tahun 2018 sampai dengan tahun 2019 jumlah kunjungan wisatawan tertinggi terjadi pada bulan Juli berturut- turut, yaitu sebanyak 30.080 dan 34908 wisatawan musium Sunan Drajat, sedangkan jumlah kunjungan wisatawan terendah terjadi pada Juli.

Tabel 1. Data Pengunjung Wisatawan Musium Sunan Drajat

\begin{tabular}{|c|c|c|c|c|}
\hline Bulan/Tahun & 2016 & 2017 & 2018 & 2019 \\
\hline Januari & 11674 & 17129 & 22584 & 28039 \\
\cline { 2 - 5 } Februari & 14955 & 17729 & 20503 & 23277 \\
\hline Maret & 14894 & 15844 & 16794 & 17744 \\
\hline April & 18186 & 21451 & 24716 & 27981 \\
\hline Mei & 18386 & 20447 & 22508 & 24569 \\
\hline Juni & 14755 & 19668 & 24581 & 29494 \\
\hline Juli & 20424 & 25252 & 30080 & 34908 \\
\hline Agustus & 10245 & 10656 & 11067 & 11478 \\
\hline September & 19907 & 21890 & 23873 & 25856 \\
\hline Oktober & 20819 & 21200 & 21581 & 21962 \\
\hline November & 23126 & 24360 & 25594 & 26828 \\
\hline Desember & 21415 & 23208 & 25001 & 26794 \\
\hline
\end{tabular}

Sumber : Observasi ke Makam Sunan Drajat (2019)

Pelatihan data dilakukan dengan Jaringan Syaraf Tiruan menggunakan Algoritma Backpropagation dengan metode pelatihan Levenberg-Marquardt dengan menggunakan Software Matlab. Pelatihan jaringan membutuhkan parameter-parameter yang digunakan untuk mengenali pola data. Parameter pelatihan dalam penelitian meliputi maksimum epochs 1000. Maksimum epoch berfungsi sebagai kriteria pemberhentian pelatihan, yaitu pelatihan dihentikan setelah mencapai 1000 iterasi. Nilai goal (MSE) adalah 0 , digunakan untuk menentukan batas nilai MSE agar iterasi dihentikan, nilai ini dipilih berdasarkan dengan trial dan error sampai dihasilkan performance dan goal yang terkecil. 
Tabel 2. Hasil Pelatihan Jaringan

\begin{tabular}{|c|c|c|}
\hline Tahun & Jumlah Neuron & MSE \\
\hline \multirow{4}{*}{} & 1 & $1,81979 \mathrm{e}-02$ \\
\cline { 2 - 3 } & 2 & $9,48075 \mathrm{e}-04$ \\
\cline { 2 - 3 } & 3 & $8,70993 \mathrm{e}-04$ \\
\cline { 2 - 3 } & 4 & $9,67804 \mathrm{e}-05$ \\
\cline { 2 - 3 } & 5 & $6,53251 \mathrm{e}-06$ \\
\cline { 2 - 3 } & 6 & $6,5146 \mathrm{e}-05$ \\
\cline { 2 - 3 } & 7 & $1,34805 \mathrm{e}-06$ \\
\cline { 2 - 3 } & 8 & $1,24251 \mathrm{e}-05$ \\
\cline { 2 - 3 } & 9 & $2,53451 \mathrm{e}-04$ \\
\hline
\end{tabular}

Sumber : Data Diolah (2019)

Jaringan terbaik dihasilkan pada pelatihan jaringan 25-1 (2 neuron input, 5 neuron hidden layer, 1 neuron output) dengan nilai MSE terkecil, yaitu 0,00000653251 .

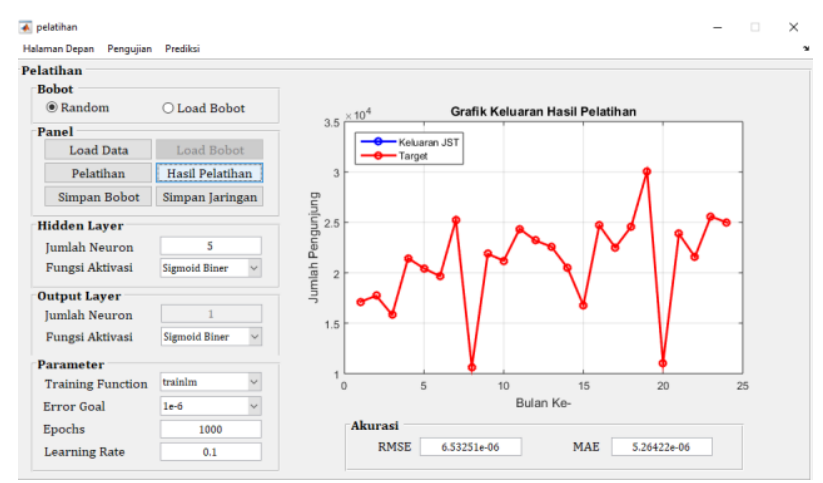

Sumber : Data Diolah (2019)

Gambar 3. Grafik Hasil Pelatihan Jumlah Pengunjung Wisata Musium Sunan Drajat

Dari gambar 3 di atas diperoleh sebuah perbandingan data keluaran JST (aktual) dengan target (ramalan). Gambar tersebut di atas telah menunjukkan kinerja yang cukup baik dilihat dari kedekatan hasil ramaln dengan aktual.

Proses pelatihan yang terlihat dari gambar di atas menggunakan desain Jaringan 2-5-1 (2 neuron input, 5 neuron hidden layer, 1 neuron output), dengan fungsi aktivasi sigmoid biner, parameter fungsi training trainim, dan epochs 1000 telah menghasilkan akurasi yang cukup bagus yakni RMSE $=6,53251 \mathrm{e}$ 06 dan MAE = 5,26422e-06.

Proses selanjutnya adalah pengujian. Pada proses ini data yang digunakan adalah data tahun 2019. Berikut ini hasil pengujian data tersebut dengan desain jaringan 2-5-1.

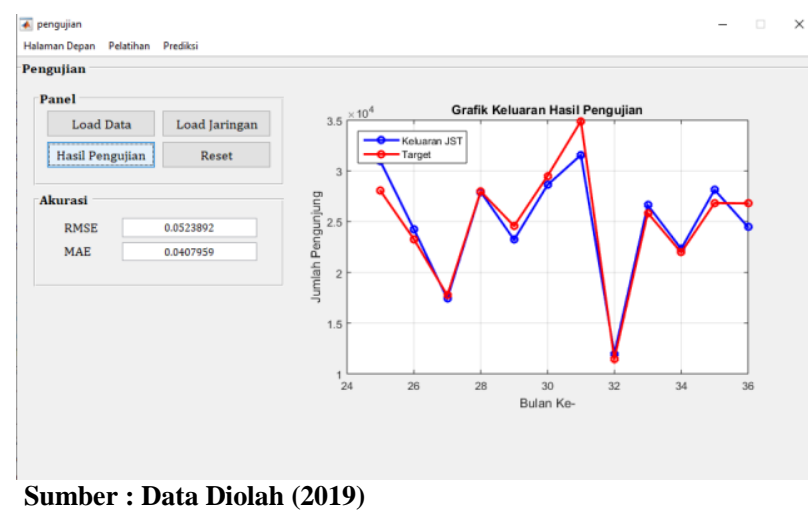

Sumber : Data Diolah (2019)

\section{Gambar 4. Grafik Hasil Pengujian Jumlah Pengunjung Wisata Musium Sunan Drajat}

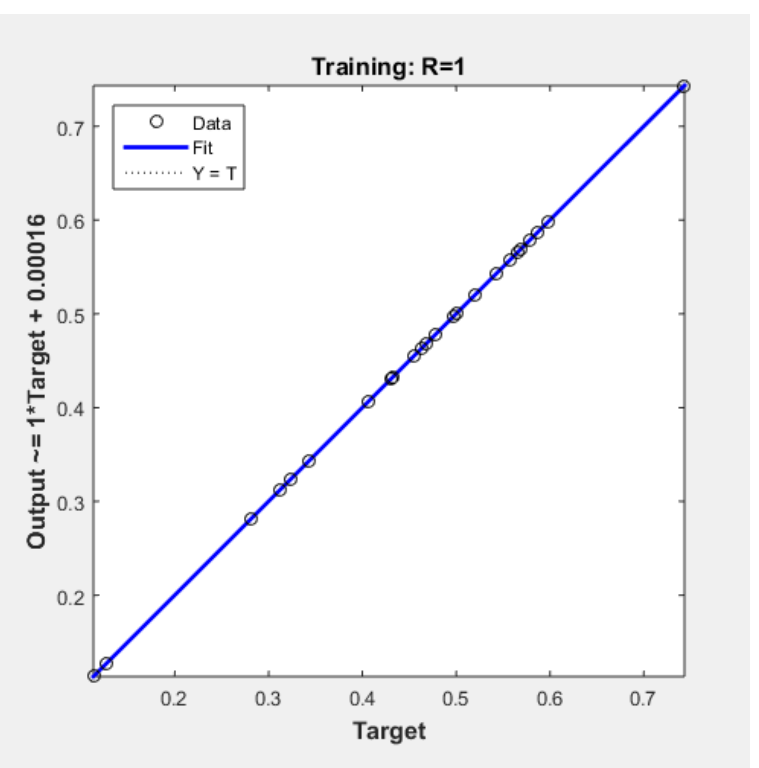

Sumber : Data Diolah (2019)

\section{Gambar 5. Grafik Regresi Hasil Pengujian Jumlah Pengunjung Wisata Musium Sunan Drajat}

Dari gambar 4 dan 5 di atas dihasilkan sebuah akurasi RMSE $=0,0523892$ dan $\mathrm{MAE}=0,0407959$ dengan sebuah korelasi regresi $=1$. Sehingga bisa disimpulkan hasil akurasi pengujian data permalan kedatangan pengunjung pada tahun 2019 sebesar $99,95 \%$.

\section{KESIMPULAN}

Artikel ini mempresentasikan penerapan metode Jaringan Syaraf Tiruan Backpropagation (BPNN) untuk memprediksi jumlah kedatangan wisatawan di musium Sunan Drajat. Data yang digunakan dalam penelitian ini adalah data primer yang didapat peneliti melalui observasi langsung ke Musium Sunan Drajat. Pelatihan dilakukan dengan menggunakan arsitektur jaringan layar banyak (Multi Layer Network) yang mempunyai input, output, dan hidden layer. Mean square error (MSE) dan Mean Absolute Error (MAE) 
digunakan untuk melihat performansi dari setiap arsitektur BPNN. Desain jaringan yang digunakan dalam training dan uji data menggunakan arsitektur 25-1 (2 neuron input, 5 neuron hidden layer, 1 neuron output), dengan fungsi aktivasi sigmoid biner , parameter fungsi training trainim, dan epochs 1000. Dari pengujian yang dilakukan terlihat bahwa metode BPNN dapat digunakan sebagai alat bantu simulasi dalam peramalan dengan menghasilkan tingkat akurasi sebesar 99,95\%.

Diharapakan kedepannya dapat dianalisis menggunakan dianalisi dengan membandingkan dengan metode lainnya seperti optimalisasi metode BPNN menggunakan algoritma seperti algoritma genetika (GA), particle swarm optimization (PSO), dan Deep Learning.

\section{PUSTAKA}

H. Hassani, A. Webster, E. S. Silva, and S. Heravi, "Forecasting U.S. Tourist arrivals using optimal Singular Spectrum Analysis," Tourism Management, vol. 46 (2015), pp. 322-335, 2015.

X. Sun, W. Sun, J. Wang, Y. Zhang, and Y. Gao, "Using a GreyeMarkov model optimized by Cuckoo search algorithm to forecast the annual foreign tourist arrivals to China," Touris Management, vol. 52 (2016), pp. 369-379, 2016.

W. Lijuan and C. Guohua, "Seasonal SVR with FOA algorithm for single-step and multi-step ahead forecasting in monthly inbound tourist flow," Knowledge-Based Systems, vol. 110 (2016), pp. 157 - 166, 2016.

O. Claveria and S. Torra, "Forecasting tourism demand to Catalonia: Neural networks vs. time series models," Economic Modelling, vol. 36, pp. 220 - 228, 2014.

Haviluddin and R. Alfred, "Forecasting Network Activities Using ARIMA Method," Journal of Advances in Computer Networks (JACN), vol. 2, (3) September 2014, pp. 173-179, 2014.

M. C. Altunel and B. Erkut, "Cultural tourism in Istanbul: The mediation effect of tourist experience and satisfaction on the relationship between involvement and recommendation intention," Journal of Destination Marketing \& Management, vol. 4 (2015), pp. 213 - 221, 2015.

C.-W. Wu, "Foreign tourists' intentions in visiting leisure farms," Journal of Business Research, vol. 68 (2015), pp. 757 - 762, 2015.

B. Majhi, M. Rout, and V. Baghel, "On the development and performance evaluation of a multiobjective GA-based RBF adaptive model for the prediction of stock indices," Journal of King Saud University Computer and Information Sciences, pp. xx-xx, 2014.

H. A. Constantino, P. O. Fernandes, and J. P. Teixeira, "Tourism demand modelling and forecasting with artificial neural network models: The Mozambique case study," TÉKHNE - Review of Applied Management Studies, vol. (2016) xxx, pp. xxx ---xxx, 2016.

O. Claveria, E. Monte, and S. Torra, "Common trends in international tourism demand: Are they useful to improve tourism predictions?," Tourism Management Perspectives, vol.16 (2015), pp. 116 - 122, 2015. 